\title{
Complex control of coordination and speed-power abilities in fire- applied sports
}

\author{
Georgiy Georgievich Polevoy ${ }^{\mathrm{ADE}}$, Irina Vasil'evna Strelnikowa ${ }^{\mathrm{ABC}}$ \\ Vyatka State University, Kirov, Russia
}

Authors' Contribution: A - Study design; B - Data collection; C - Statistical analysis; D - Manuscript Preparation; E - Funds Collection.

\begin{tabular}{|c|c|}
\hline \multicolumn{2}{|l|}{ Abstract } \\
\hline Purpose: & $\begin{array}{l}\text { To identify informative tests for complex control of coordination and speed-power abilities in fire-applied } \\
\text { sports. }\end{array}$ \\
\hline Material: & $\begin{array}{l}38 \text { experienced firefighter-athletes aged } 15-17 \text {, who have been doing this sport for } 5-6 \text { years, took part in } \\
\text { the research. The survey of Russian leading coaches allowed us to make up a bank of } 20 \text { tests. The Brave- } \\
\text { Pearson correlation coefficient was used in the statistical processing of the results. The research results } \\
\text { were processed using the Excel program. }\end{array}$ \\
\hline Results: & $\begin{array}{l}\text { Methods of controlling coordination and speed-power abilities with competitive result when overcoming } \\
\text { a } 100 \text {-meter obstacle course in fire-applied sports were experimentally substantiated. In accordance with } \\
\text { the basic metrological requirements, close correlation relationship was found for } 10 \text { tests. }\end{array}$ \\
\hline Conclusions: & $\begin{array}{l}\text { Fire-applied sports is a complex technical type, to control the development of coordination and speed- } \\
\text { power abilities it is necessary to rely not on one test, but on a bank of them. The identified informative } \\
\text { tests can be recommended for complex monitoring of coordination and speed-power preparedness in } \\
\text { fire-applied sports. }\end{array}$ \\
\hline Keywo & fire-applied sports, obstacle course, coordination abilities, speed-power abilities, complex control. \\
\hline
\end{tabular}

\section{Introduction}

Currently, testing is one of the main methods of pedagogical control of the level of physical fitness of athletes in various sports [1-3]. In studies of domestic and foreign experts, the issues of diagnosing coordination and speed-power abilities are represented quite widely [4-6]. However, various criteria are used to evaluate them, and there is no one of them that is generally accepted $[4,7]$.

Most researchers suggest using a different number of tests to determine athletic fitness of athletes: from 2-3 to 11-20 [7-9]. The entire selection of test tasks should be based on the most significant abilities for each sport. On the one hand, it allows getting a more reliable assessment of the level of development of each individual ability; on the other hand, the positive relationship of the test data with the competitive exercise can be determined [9].

The discussed kind of sport is determined by the peculiarities of the professional activities of firefighters and is associated with the implementation of various techniques at high speed $[10,11]$. One of the sport exercises is to overcome a 100-meter obstacle course. The effectiveness of competitive activity in this discipline requires high coordination and speed-power abilities [12-14]. Therefore, the basis of pedagogical control in fire-fighting athletes is the diagnosis of coordination and speed-power preparedness $[12,15]$.

Despite there are some researches of this issue, we were not able to find scientifically based data for assessing coordination and speed-power abilities with competitive result when overcoming a 100-meter obstacle course in fire-applied sports. This analysis allowed us to determine the relevance of our study.

( ) Georgiy Georgievich Polevoy, Irina Vasil'evna Strelnikowa, 2020 doi:10.15561/26649837.2020.0606

\section{Material and methods}

Participants. The research was carried out on the basis of the Prometey sports complex in Kirov (Russia) among firefighting athletes aged 15-17. In total 38 experienced athletes participated, who have been doing this sport for 5-6 years. All procedures complied with the ethical standards of the 1964 Helsinki Declaration. All parents of participants who took part in the study signed the informed consent.

Procedure. The free interview, as one of the survey methods, made it possible to maximally adapt the questions of the previously prepared interview form. Interviews were conducted according to the professional status of the respondents. The survey involved 16 coaches (Russia) from Moscow, the Moscow region, the Nizhny Novgorod region, the Perm region, the Sverdlovsk region, the Chelyabinsk region, and the Kirov region.

During the study, 20 tests for determining coordination and speed-power preparedness in fire-applied sports were selected. However, only 10 tests showed an average statistical relationship with competitive result when overcoming a 100-meter obstacle course.

For determining the level of coordination preparedness $[4,5,15]$ :

1. Shuttle run $3 \times 10 \mathrm{~m}(\mathrm{~s}),(\mathrm{r}=0,698)[4,5,15]$.

Task conditions: from the high start by the command "Go!" the athlete ran $10 \mathrm{~m}$ at the maximum speed, then the athlete ran around any side of the stuffed ball. Next he came back and again ran around the ball. The third time, after $10 \mathrm{~m}$, he finished. The test result - running time was measured in seconds from the command "March" to crossing the finish line.

2. Double side jump standing on both legs (sm), 
$(\mathrm{r}=-0,680)$ [5].

Task conditions: the athlete was side standing at the line of the direction of movement. He made two jumps in a row standing on two legs. The result was measured from the beginning of the line to the place of landing. The best result of two attempts in sm was recorded.

3. Turns on the gymnastic bench (number of times), $(\mathrm{r}=-0,624)[5]$.

Task conditions: the athlete stood on the narrow surface of the bench. For 20 seconds, he made 360-degree turns, alternating left and right. If the athlete lost balance, then he resumed the test. The number of completed turns was recorded to the accuracy of a half-turn.

To determine the level of motor coordination of hands ("manual dexterity") [16-18]:

4. Dashes - catching a tennis ball number of times), (r=-0,691) [16, 18].

Task conditions: the athlete was facing the wall at one-meter distance. He held 2 tennis balls in one hand. By command, he threw one ball into the wall one after another. After each hit he tried to catch the ball. This task continued to be completed for 10 seconds. Two trial and two main attempts were given. The number of best caught balls in the best attempt was recorded.

5. Juggling a tennis racket (number of times), ( $\mathrm{r}=$ $0,646)[17,18]$.

Task conditions: the tested, by command, began to juggle the tennis ball alternately on the right and left sides of the racket for 10 seconds. Two trial and two final attempts were given. The number of punches in the best attempt was recorded.

To determine the level of development of speed-power abilities $[8,18,19]$ :

6. $100 \mathrm{~m}$ run from crouch start $(\mathrm{s})(\mathrm{r}=0,633)[8,19]$.

Task conditions: from the crouch start position by command, the athlete ran this distance. The time from the "Go!" command until crossing the finish line in seconds was recorded.
7. $30 \mathrm{~m}$ run from high start $(\mathrm{s})(\mathrm{r}=0,689)[8,18]$.

Task conditions: from the high start by command, the athlete ran this distance. Time from the "Go!" command until the finish in seconds was recorded.

8. Standing triple jump $(\mathrm{m})(\mathrm{r}=0,633)[8]$.

Task conditions: the stood at the line, feet at shoulder length. Three jumps were done alternately from one leg to the other. Landing was on two legs. The result was measured from the line to the place of landing in sm (the heel of the athlete closest to the line). The best result of three attempts was recorded.

When receiving complex information on motor coordination, the main emphasis was on the combined tests or tests of repeated tasks, which also showed their reliability.

For complex assessment of speed-power and coordination abilities, the sport-motor test proposed by E. Zieris in the form of an obstacle course was used [7].

9. Sport-motor test $(\mathrm{r}=0,697)$.

This test has been modified to reflect the specifics of fire-applied sports to the greatest extent. The test with benches of Ljach is included in this course, but it has been changed since it was used for primary school children [9]. The main difference of the test was that the tested had to run on benches, and not crawl along them in the crawling position.

As a result of the modification, the sport-motor test consisted of the following stages (Fig. 1):

- acceleration;

- forward roll;

- running on the benches;

- going along the gym wall-bars at will;

- jumping over the barrier;

- running around the medball;

- crawling under the barrier;

- jump on the hill of mats;

- finish.

Task conditions. The athlete ran at maximum speed

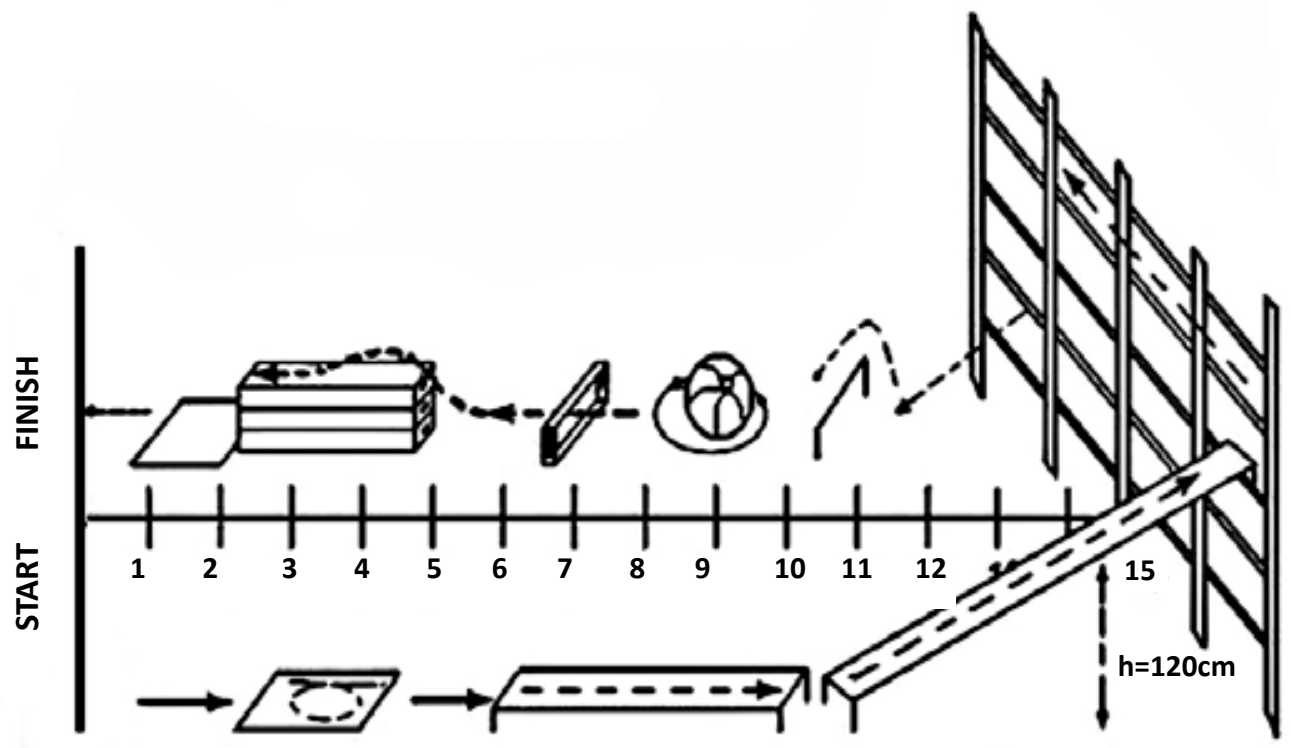

Fig. 1. Sport-motor test 
all the distance. From a high start by the command "Go!" after $2 \mathrm{~m}$ the athlete did a forward roll. After $3 \mathrm{~m}$ he ran on gymnastic benches. The far edge of the second bench was fixed on the gym wall-bars at the height of $120 \mathrm{~cm}$. Over the gym wall-bars he overcame 4 flights. He came down and after $3 \mathrm{~m}$ he jumped over the barrier $76 \mathrm{~cm}$ high. Again he ran $2 \mathrm{~m}$. He ran around the medball. After $2 \mathrm{~m}$, he crawled under the barrier $120 \mathrm{~cm}$ high. After $4 \mathrm{~m}$, he jumped onto sport mats $120 \mathrm{~cm}$ high. He jumped and finished after $3 \mathrm{~m}$. The best result of passing the distance in two attempts in seconds was recorded.

To assess the level of coordination, speed-power and professional abilities, the control exercise was developed in the form of a 30-meter obstacle course [12, 21, 22]:

10. Technical course (s).

It was assumed that this course most fully simulates the techniques of firefighters in relation to a 100 -meter obstacle course. It requires complex manifestation at the maximum level of all physical and professionally important abilities.

The distance of $30 \mathrm{~m}$ consisted of the following tasks (Fig. 2):

- acceleration 10m;

- two forward rolls;

- connecting two blank caps;

- joining the blank cap to the fire manifold;
- finish.

Task conditions. From the high start by the command "Go!" the athlete ran $10 \mathrm{~m}$. He did two forward rolls mats in a row. He connected two blank caps, which were $20 \mathrm{~m}$ from the start line. He ran 5 meters to the fire manifold and attached it to the blank cap, which lay to the right at the distance $50 \mathrm{sm}$ from the ire manifold. Then he finished. The best result of passing the distance in seconds by attempts was recorded. If one of the combinations was not completed, then the control exercise was failed.

Statistical analysis:

The use of mathematical statistics methods showed that not a single test has a high correlation with the competitive result [22]. For calculation the BravePearson correlation coefficient was used. The correlation coefficient characterized the linear interrelation, i.e. degree of crowding. The results were processed using Excel. The result was significant at $\mathrm{P}<0.05$.

\section{Results}

The true interrelation was determined in 10 tests ( $p>$ $0.05)$. The correlation coefficient was in the range $\mathrm{r}=$ $-0.618-0.698$, which corresponds to the statistical criteria of reliability, objectivity and informativeness. Other tests showed a low correlation coefficient $r=0.3(p<0.05)$. (Table).

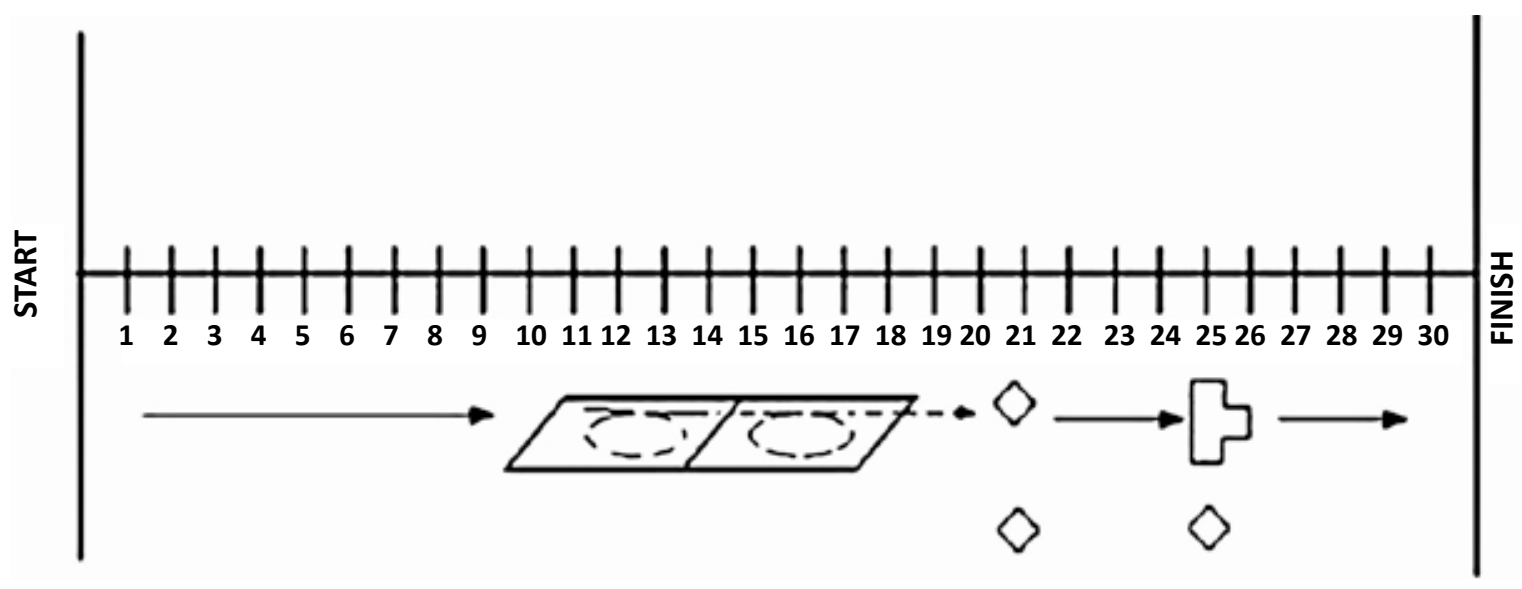

Fig. 2. Scheme of the technical course

Table. Calculation of the correlation coefficient to the competitive result $(n=38)$

\begin{tabular}{|c|c|c|}
\hline Control tests & $\mathbf{r}$ & Dependence \\
\hline $1.100 \mathrm{~m}$ from crouch start (s) & 0.633 & $p>0.05$ \\
\hline 2. Running around three racks (s) & 0.426 & $p<0.05$ \\
\hline 3. $30 \mathrm{~m}$ from high start (s) & 0.689 & $p>0.05$ \\
\hline 4. High thigh lift upperarm support standing at the gym wall-bars for 10 seconds & -0.496 & $p<0.05$ \\
\hline 5. Complex agility exercise (s) & 0.499 & $\mathrm{p}<0.05$ \\
\hline 6. Double side jump standing on both legs (m, sm) & -0.680 & $p>0.05$ \\
\hline 7. Jumps downward on markings (m, sm) & 0.142 & $\mathrm{p}<0.05$ \\
\hline 8. Shuttle run $3 \times 10 \mathrm{~m}(\mathrm{~s})$ & 0.698 & $p>0.05$ \\
\hline 9. Long jump for touch-down accuracy without visual analyser (m, sm) & 0.301 & $p<0.05$ \\
\hline 10. Shuttle run $3 \times 10 \mathrm{~m}$ backward (s) & 0.383 & $p<0.05$ \\
\hline 11. Turns on the gymnastic bench (num. of times) & -0.624 & $p>0.05$ \\
\hline
\end{tabular}




\begin{tabular}{lll}
\hline Control tests & $\mathbf{r}$ & Dependence \\
\hline 12. Accurate rolling the ball by hand (sm) & -0.256 & $\mathrm{p}<0.05$ \\
13. Dashes - catching a tennis ball (num. of times) & -0.691 & $\mathrm{p}>0.05$ \\
14. Jump in place and max-degree turn in the air (degrees) & -0.234 & $\mathrm{p}<0.05$ \\
15. Sport-motor test (s) & $\mathbf{0 . 6 9 7}$ & $\mathbf{p}>\mathbf{0 . 0 5}$ \\
16. Overstepping gym-sticks (num. of times) & -0.356 & $\mathrm{p}<0.05$ \\
17. Juggling a tennis racket (num. of times) & $-\mathbf{0 . 6 4 6}$ & $\mathbf{p}>\mathbf{0 . 0 5}$ \\
18. Technical course (shortened) (s) & 0.682 & $\mathrm{p}>0.05$ \\
19. Temping-test (num. of times) & 0.402 & $\mathrm{p}<0.05$ \\
20. Standing triple jump (m, sm) & -0.618 & $\mathrm{p}>0.05$ \\
\hline
\end{tabular}

\section{Discussion}

The researches in the field of testing prove the close relationship between leading moving abilities and the competitive exercise in various sports [2, 5, 23, 24].

Some authors argue that the evaluation criteria should be indicators of the effectiveness of the implementation of Integral actions and their combination for a particular sport. However, in some literary sources, tests are presented not as a system of control tests, but as a set of tasks without proper scientific justification [4, 25, 26]. And it cannot be considered correct.

The authors argue that using one test, even a very complex one, which consists of several motor tasks, it is impossible to obtain accurate, differentiated assessments of the level of development of athletes. Also, according to the results of one or more informative tests, it is wrongful to judge the degree of formation of all abilities $[5,7,27$, 28].

In this regard Russian and foreign colleagues point to the need for complex monitoring. Applied tests should give simultaneous information on the degree of development of leading abilities and competitive results $[3,4,27]$. Thus, a number of authors indicate the influence of coordination and speed-power indicators on the technical skills of athletes in cyclic sports $[5,18]$.

Currently, the literature has sufficiently fully disclosed criteria for evaluating speed-power preparedness in relation to various sports $[23,26]$. Nevertheless, the problem of controlling coordination abilities is not yet fully covered $[9,29]$.

Ljach systematized criteria for assessing coordination abilities, which are currently congruent with data received by other authors $[6,9,18]$. The researchers prove that each criterion is not a single and single-valued indicator characterizing coordination abilities, but they are quite complex and multivalue, because they are specifically manifested in various combinations with each other in any motor activity. Moreover, the quality components of correctness are adequacy and accuracy, of quickness - timeliness and speed, of rationality - expediency, of resourcefulness - initiative [5, 6, 9]. These assessment criteria are generalizing concepts that are specified in determining the appropriate special and specific coordination abilities $[4,9]$.

However, scientists do not consider them in conjunction with speed-power abilities. Also, in the available literature, we did not find publications containing information on assessing the level of development of speed-power and coordination abilities in fire-applied sports.

In the new study, the static processing method was applied, which allowed to identify informative tests in fireapplied sports. These tests allow diagnosing coordination and speed-power indicators and can be used in a complex study of these abilities.

\section{Conclusion}

The results revealed the informative tests for the diagnosis of speed-power and coordination abilities in fire-applied sport. The reliable correlation was found between coordination and speed-power abilities when overcoming a 100-meter obstacle course. It allows us to talk about achieving the aim and complete solution of the research tasks. The results of the study can be applied for firefighters.

\section{Conflict of interest}

The authors declare that there is no conflict of interests. 


\section{References}

1. Ljach WI. Theory of Tests and Testing of Physical Preparation of Students. Physical Culture in School. 2007;6:2-7. (In Russian)

2. Pojskić H, Šeparović V, Muratović M, Uièanin E. The relationship between physical fitness and shooting accuracy of professional basketball players. Motriz. Revista de Educacao Fisica. 2014;4(20):408-417. https://doi.org/10.1590/S1980-65742014000400007

3. Read PJ, Hughes J, Stewart P, Chavda S, Bishop $\mathrm{C}$, Edwards $\mathrm{M}$, et al. A needs analysis and fieldbased testing battery for basketball. Strength and Conditioning Journal. 2014;3(36):13-20. https://doi.org/10.1519/SSC.0000000000000051

4. Savu CF, Pehoiu C. Particularities of the Education of the Coordination and Acquisition of the Curriculum of Physical Education by Using the Specific Means of Playing Basketball. Revista Romaneasca Pentru Educatie Mul Tidimensionala. 2018;4(10): 217-227. https://doi.org/10.18662/rrem/83

5. Ljach WI, Witkowski Z. Development and training of coordination skills in 11- to 19-year-old soccer players. Human Physiology. 2010;1(36):64-71. https://doi.org/10.1134/S0362119710010081

6. Cazzola D, Pavei G, Preatoni E. Can coordination variability identify performance factors and skill level in competitive sport? The case of race walking. Journal of Sport and Health Science. 2016;1(5): 35-43. https://doi.org/10.1016/j.jshs.2015.11.005

7. Zieris E. To use a complex versatility test. Theory and practice of physical culture, 1984;2: 124-125. (In Russian)

8. Palagina N, Dorogova YA, Polevshchikov M, Familnikova NV. Standardization of Testing the Level of Physical Fitness of Students of 18-20 years. Mediterranean Journal of Social Sciences. 2015;6(3): 887-896. https://doi.org/10.5901/mjss.2015.v6n3s7p265

9. Ljach WI. Development of coordination abilities in schoolage children. Moscow; 1990. (In Russian)

10.Germanov G.N, Smorchkov VA, Mashoshina IV. Adequacy of means and methods of professional and applied physical training of cadets of institutes of the public fire service of Emercom of Russia to requirements of office activity. Uchenye zapiski universiteta imeni P.F. Lesgafta. 2014;2(108): 57-60. (In Russian) https://doi.org/10.5930/issn. 1994-4683.2014.02.108

11. Berges A, Fernandez-Del-Rio E, Ramos-Villagrasa PJ. The Prediction of Training Proficiency in Firefighters: A Study of Predictive Validity in Spain. Journal of work and organizational psychology, 2018;34(1): 10-15.

12.Kalinin AP. Modern firefighting and rescue sport: studies. a grant for a wide range of fans of rescue and firefighting sport, athletes of various qualification, listeners of educational institutions of Emercom of Russia, experts and rescue and firefighting sport coaches. Moscow: Russian Federation; 2004. (In Russian)

13.Kleinberg CR, Ryan ED, Tweedell AJ, Barnette TJ, Wagoner $\mathrm{CW}$. Influence of lower extremity muscle size and quality on stair-climb performance in career firefighters. Journal of Strength and Conditioning Research. 2016;6(30): 1613-1618. https://doi.org/10.1519/JSC.0000000000001268

14. Wiszomirska I, Iwanska D, Tabor P. Postural stability pattern as an important safety factor of firefighters. Work-A Journal of Prevention Assessention \& Rehabilitation. 2019;62(3): 469-476. https://doi.org/10.3233/WOR-192881
15.Gumieniak RJ, Gledhill N, Jamnik VK. Physical employment standard for Canadian wildland firefighters: examining testretest reliability and the impact of familiarisation and physical fitnesstraining.JournalErgonomics. 2018;10(61):1324-1333. https://doi.org/10.1080/00140139.2018.1464213

16.Dong H, Figueroa N, El Saddik A. "Load Balance" Control for a Humanoid Musculoskeletal Arm in Table Tennis Movement. International Journal of Control Automation and Systems, 2015;4(13): 887-896. https://doi.org/10.1007/s12555-014-0038-Z

17.Morel ÉA, Zagatto AM. Adaptation of the lactate minimum, critical power and anaerobic threshold tests for assessment of the aerobic/anaerobic transition in a protocol specific for table tennis. Revista Brasileira de Medicina do Esporte. 2008;6(14):518-522. https://doi.org/10.1590/S1517-86922008000600009

18.Wong TKK, Ma AWW, Liu KPY, Chung LMY, Bae YH, Fong SSM, Ganesan B, Wang HK. Balance control, agility, eye-hand coordination, and sport performance of amateur badminton players: A cross-sectional study. Medicine. 2019;2(98):13-20. https://doi.org/10.1097/MD.0000000000014134

19.Sport. Testing physical fitness. Eurofit. Experimental battery. Provisional handbook [Internet]. 2011. [updated 2020; cited 2020 March 23]. Available from: https://bitworksengineering.co.uk/linked/eurofit $\% 20$ provisional $\% 20$ handbook\%20leger\%20beep\%20test\%201983.pdf

20.Germanov GN, Korolkov AN, Shalaginov VD, Smorchkov VA, Mashoshina IV, Georgieva MP. Model characteristics of the competitive activity of athletes of various age and sexual groups in rescue and firefighting sport. Uchenye zapiski universitetaimeniP.F.Lesgafta.2016;6(30):60-69.(InRussian) https://doi.org/10.5930/issn.1994-4683.2016.01.131

21.Shalaginov VD, Korolkov AN, Smorchkov VA. Definition of an optimum ratio of speed of run and braking when performing connection of the fire hose line to a branching in fire and applied sport. Uchenye zapiski universiteta imeni P.F. Lesgafta, 2015; 4(117): 196-199. (In Russian) https://doi.org/10.5930/issn.1994-4683.2015.04.122

22.Kim TK. T test as a parametric statistic. Korean Journal of Anesthesiol. 2015;68(6):540-546. https://doi.org/10.4097/kjae.2015.68.6.540

23.Zheleznyak UD, Petrov PC. Fundamentals of scientific and methodological activities in physical education and sport. Moscow: Academy; 2002. (In Russian)

24.Akgül M. Effect of Wingate-based high intensity interval training on aerobic and anaerobic performance of kick boxers. Physical Education of Students. 2019;23(4):167-71. https://doi.org/10.15561/20755279.2019.0401

25.BurrJF,JamnikRK,BakerJ,MacphersonA, GledhillN,Mcguire EJ. Relationship of physical fitness test results and hockey playing potential in elite-level ice hockey players. Journal of Strength and Conditioning Research. 2008;22(5):1535-1543. https://doi.org/10.1519/JSC.0b013e318181ac20

26.Loturco I, Contreras B, Kobal R, Fernandes V, Moura N, Siqueira F, Winckler C, Suchomel T, Pereira LA. Vertically and horizontally directed muscle power exercises: Relationships with top-level sprint performance. PLoS ONE. 2018;13(7):1-12. https://doi.org/10.1371/journal.pone.0201475

27.Wang PF, Tu MH, Fu LL. Results of Graded Exercise and Specific Fitness Test of Table Tennis Players. Medicine and Science in Sport and Exercise. 2014;5(46): 55-55. https://doi.org/10.1249/01.mss.0000493331.97748.e8

28.Genc H, Cigerci A, Sever O. Effect of 8-week core training exercises on physical and physiological 
parameters of female handball players. Physical Education of Students. 2019;23(6):297-05. https://doi.org/10.15561/20755279.2019.0604
29.ZerfM, Hadjar Kherfane M, Kohli K, Louglaib L. Relationship Between Maximum Aerobic Speed Performance and Volleyball Game Motor Power-Explosive Abilities. Teoriâ ta Metodika Fizičnogo Vihovannâ, 2019; 19(4), 179-185. https://doi.org/10.17309/tmfv.2019.4.03

\section{Information about the authors:}

Georgiy Georgievich Polevoy; (Corresponding author); http://orcid.org/0000-0002-3300-3908; g.g.polevoy@gmail.com; Department of Physical Education. Vyatka State University, Russia.

Irina Vasil'evna Strelnikowa; https://orcid.org/0000-0002-2715-7513; irina.strelnikowa2017@yandex.ru; Department of Physical Education. Vyatka State University; Moscow, Russia.

Cite this article as:

Polevoy GG, Strelnikowa IV. Complex control of coordination and speed-power abilities in fire-applied sports. Pedagogy of Physical Culture and Sports, 2020;24(6):310-315.

https://doi.org/10.15561/26649837.2020.0606

This is an Open Access article distributed under the terms of the Creative Commons Attribution License, which permits unrestricted use, distribution, and reproduction in any medium, provided the original work is properly cited (http://creativecommons.org/licenses/by/4.0/deed.en).

Received: 02.05.2020

Accepted: 12.06.2020; Published: 30.12.2020 